ARTÍCULOS

CRÍTICA, Revista Hispanoamericana de Filosofía

Vol. XXXII, No. 94 (abril 2000): 3-27

\title{
EL ATAQUE DE PUTNAM AL REALISMO METAFÍSICO
}

ELEONORA ORLANDO

Universidad de Buenos Aires

En Razón, verdad e historia, Putnam presenta una nueva concepción ontológica o metafísica que denomina "realismo interno", postura contrapuesta al realismo metafísico. ${ }^{1}$ En mi opinión, sus principales argumentos en contra de este último y en favor de la primera son los siguientes: por un lado, el conocido argumento denominado "modeloteórico"; por otro, un argumento fundado en la inexistencia de una única descripción completa y verdadera del mundo que caracterizaré como "argumento basado en el perspectivismo". En este artículo, me propongo destacar que ambos argumentos son afectados por el mismo tipo de problema: presuponen equivocadamente que el realismo metafísico nos compromete necesariamente con ciertas doctrinas, más específicamente la teoría correspondentista de la verdad y la tesis de la existencia de una única descripción completa y verdadera del mundo. $\mathrm{Si}$, como creo que es posible sostener, el realismo metafísico es conceptualmente independiente de tales doctrinas, la argumentación de Putnam en su contra fracasa en su objetivo fundamental.

1 Véase Putnam 1981. 
En síntesis, considero que los argumentos ofrecidos por Putnam en contra del realismo metafísico dependen de la manera en que el autor caracteriza tal postura; ahora bien, esta caracterización no es, en mi opinión, adecuada, puesto que involucra doctrinas que le son ajenas; por consiguiente, los argumentos en cuestión, orientados fundamentalmente hacia estas doctrinas, no logran afectar el núcleo central del realismo metafísico.

El artículo está dividido en dos partes principales. En la primera, reproduzco el argumento modelo-teórico, para luego señalar que se apoya en una premisa falsa: que la teoría de la verdad como correspondencia es parte constitutiva del realismo metafísico - por lo que la falsedad de la primera, en contra de lo sostenido por Putnam, no implica la falsedad del segundo. Desde mi punto de vista, el realismo metafísico y la teoría de la verdad como correspondencia son doctrinas conceptualmente distintas y mutuamente independientes. En la segunda parte, centrada en el argumento basado en el perspectivismo, reitero que se parte de una premisa falsa: en este caso, la idea de que el realismo metafísico involucra un punto de vista trascendente o "del Ojo de Dios". En mi opinión, el realismo metafísico, ya sea en combinación con la teoría de la correspondencia o con alguna otra concepción no epistémica de la verdad, es perfectamente compatible con la existencia de múltiples descripciones completas y verdaderas del mundo, es decir, con la tesis del perspectivismo o relativismo conceptual.

\section{Sobre el alcance del argumento modelo-teórico}

Mi objetivo no es tanto analizar el conocido argumento modelo-teórico sino cuestionar el alcance que Putnam intenta darle; en otras palabras, lo que me interesa destacar es que aun cuando el argumento en cuestión fuere un buen argumento se trataría de un argumento exclusivamente en 
contra de la teoría de la verdad como correspondencia y, por tanto, sin ningún alcance metafísico: contrariamente a lo pretendido por Putnam, considero que el realismo metafísico no se vería afectado por un posible fracaso de la correspondencia establecido por el argumento en cuestión.

Comenzaré entonces por recordar sucintamente los términos del argumento. De acuerdo con éste, si bien mediante una serie de restricciones operacionales y teóricas (esto es, aquellas restricciones que los investigadores racionales aceptarían en el límite ideal de la investigación) es posible determinar qué oraciones son verdaderas en un lenguaje determinado, no es posible hacer lo mismo con la referencia de los términos que figuran en ellas. Por un lado, las restricciones en cuestión no fijan directamente la referencia de los términos. Por otro, tampoco es posible lograr este objetivo de manera indirecta, es decir, a través de la determinación de las condiciones de verdad de las oraciones, puesto que estas últimas subdeterminan la referencia de los términos componentes: para cada oración del lenguaje, una misma asignación de condiciones veritativas es compatible con asignaciones alternativas de esquemas referenciales; en otras palabras, es posible permutar sistemáticamente la referencia de los términos sin que por ello varíen las condiciones veritativas de la oración (en ningún mundo posible). Esto implica que, a la luz de cualesquiera restricciones operacionales y teóricas, dada una oración como

El gato está sobre la alfombra

no hay modo de elegir la interpretación de los términos que llamaríamos "estándar", según la cual "gato" refiere al conjunto de los gatos y "alfombra" refiere al conjunto de las alfombras, entre múltiples otras - entre las cuales se halla aquélla según la cual "gato" refiere al conjunto 
de las cerezas y "alfombra" al conjunto de los árboles. ${ }^{2}$ El concepto de referencia, esto es, del valor semántico de los términos, no es por tanto un concepto cuyo contenido pueda ser objetivamente determinado.

Una manera alternativa de presentar el argumento anterior es la siguiente. Un teórico naturalista de la referencia sostiene como verdadera una tesis tal como

(1) $x$ refiere a $y$ si y sólo si $x$ mantiene la relación $\mathrm{R}$ con $y$

donde $\mathrm{R}$ es una relación definible en el campo de la ciencia natural, sin usar nociones semánticas —más específicamente, $\mathrm{R}$ suele ser definida fundamentalmente en términos causales. Ahora bien, si (1) es verdadera, (1) está determinada por restricciones operacionales y teóricas, es decir, es ella misma una oración que formaría parte de nuestra teoría acerca del mundo en el límite ideal de la investigación. Pero entonces (1) podrá ser interpretada de múltiples maneras: la interpretación de " $x$ mantiene $\mathrm{R}$ con $y$ " fijará la interpretación de " $x$ refiere a $y$ ", pero lo hará sólo relativamente a cierto punto de vista teórico previamente adoptado.

Vale la pena entonces destacar la conclusión establecida: el concepto de referencia carece de contenido objetivo y, por lo tanto, de valor explicativo en una teoría del significado. Pero la teoría de la verdad como correspondencia es, por lo menos en sus versiones más aceptables, una teoría del significado que asigna un papel explicativo central al concepto de referencia. Por lo tanto, el argumento modelo-

${ }^{2}$ En la versión original del argumento se recurre a propiedades extrañas, como las de ser un gato* y una estera*, las cuales son definidas en términos de ciertos conjuntos de situaciones que se dan en distintos mundos posibles. En la versión presente, dado que no hacen a la esencia del argumento, las he evitado con el objeto de simplificar la presentación. 
teórico es claramente un argumento en contra de la teoría de la verdad como correspondencia. Como mencioné anteriormente, no me propongo analizarlo ni evaluar si es bueno o malo; por el contrario, daré por sentado que es un buen argumento en contra de la teoría de la correspondencia. Lo que me interesa cuestionar es la idea putnamiana de que el argumento modelo-teórico constituye asimismo un argumento en contra del realismo metafísico.

La explicación de este punto involucra la especificación de lo que Putnam entiende por "realismo metafísico". Según Putnam, el realismo metafísico se identifica con lo que él denomina "perspectiva externalista". Dos tesis fundamentales caracterizan esta postura:

(i) el mundo consta de una totalidad fija de objetos que existen independientemente de la mente;

(ii) hay una única descripción verdadera y completa de cómo es el mundo.

Putnam puntualiza que el concepto de verdad involucrado debe ser entendido en términos de una relación única y universal de correspondencia entre las palabras o los conceptos mentales, por un lado, y los objetos del mundo, por otro, y que el establecimiento de esta relación presupone la adopción del llamado "punto de vista del Ojo de Dios", esto es, un punto de vista trascendente, que no pertenece a ningún individuo ni grupo de individuos en particular. De este modo, claramente presupone que (a) el realismo metafísico incluye como parte constitutiva cierta teoría acerca de la verdad: la teoría de la verdad como correspondencia y (b) la teoría de la correspondencia involucra a su vez la tesis de que hay una única descripción verdadera y completa del mundo, a saber, la realizada desde el punto de vista del Ojo de Dios. En síntesis, Putnam presupone la existencia de un vínculo muy estrecho, de tipo conceptual, entre el realismo metafísico y la teoría de la correspondencia: 
según Putnam, y tal como se pone de manifiesto en (ii), la teoría de la correspondencia es un componente conceptual del realismo metafísico. Es por ello que, desde su punto de vista, un argumento en contra de la primera como el argumento modelo-teórico constituye un argumento en contra del segundo.

De este modo, en términos más estrictos, el primer argumento de Putnam en contra del realismo metafísico que me propongo analizar podría ser reconstruido de la siguiente manera:

(1) Sobre la base del argumento modelo-teórico, es posible establecer que no hay una única descripción verdadera y completa de cómo es el mundo, lo cual involucra las siguientes subtesis: (a) no hay relación de correspondencia entre el lenguaje y el mundo y (b) dado que la relación de correspondencia es única, no hay una única relación entre el lenguaje y el mundo.

Luego, (2) No existe un mundo de objetos que existan independientemente de la mente.

La relación entre (1) y (2) es concebida como una relación deductiva puesto que, como destaqué anteriormente, el vínculo entre la teoría de la correspondencia (puesta en duda en (1)) y el realismo metafísico (cuestionado en (2)) es conceptual: de acuerdo con la concepción putnamiana del realismo metafísico, la teoría de la correspondencia es parte constitutiva de aquél — como señala la antes mencionada tesis (ii).

Ahora bien, en mi opinión, la concepción del realismo metafísico propuesta por Putnam es, por lo menos, discutible; en otras palabras, no está claro que el realismo metafísico tenga como parte constitutiva a la teoría de la verdad como correspondencia: por el contrario, cabe pensar que se trata de dos doctrinas conceptualmente indepen- 
dientes entre sí. Como consecuencia de ello, tampoco está claro que el argumento modelo-teórico, aun cuando fuere un buen argumento en contra de la teoría de la correspondencia, logre afectar de algún modo al realismo metafísico.

Desde mi punto de vista, el realismo metafísico es una teoría ontológica general que, en tanto tal, no tiene por qué incluir como parte constitutiva ninguna tesis semántica. De acuerdo con ello, se trata de una teoría acerca del mundo en general, según la cual los hechos, objetos, propiedades y/o eventos que lo integran son de naturaleza no mental y existen independientemente de nuestras capacidades subjetivas, tanto epistémicas como semánticas y pragmáticas. Podría decirse, siguiendo a Devitt, que el realismo metafísico tiene dos dimensiones:

(i) una dimensión de existencia, cuya explicitación involucra una especificación de los tipos de entidades que conforman el compromiso ontológico realista;

(ii) una dimensión de independencia, cuya explicitación pone de manifiesto el rasgo de independencia de lo mental y objetividad de tales entidades; en otras palabras, desde el punto de vista realista, las entidades que constituyen el mundo, cualesquiera que éstas sean, no son de naturaleza mental (como lo son, por ejemplo, las ideas de Berkeley) y son objetivas, en el sentido de que no dependen para existir de las capacidades del sujeto (como es el caso, por ejemplo, de los fenómenos kantianos). ${ }^{3}$

3 Véase Devitt 1991, cap. 2. Nótese que la objetividad es definida en términos de independencia, en lo que concierne a la existencia, respecto de las capacidades del sujeto. De este modo, los fenómenos kantianos, si bien son objetivos en el sentido de Kant, esto es, constituyen los objetos de conocimiento, no lo son en el sentido anterior, por cuanto son en parte constituidos por las estructuras a priori del sujeto trascendental. 
Esto último se basa en el hecho de que hay dos maneras claras de sostener una postura antirrealista en metafísica: o bien se considera que las entidades que constituyen el mundo son de naturaleza mental (como es el caso de Berkeley, para quien el mundo está constituido por ideas subjetivas, concepción que dio lugar al denominado "idealismo subjetivo" ${ }^{4}$ o bien se considera que las entidades que constituyen el mundo, si bien no están hechas de sustancia mental, dependen para existir de las capacidades del sujeto (como es el caso de Dummett, para quien lo que existe está constituido por las capacidades epistémicas y semánticas del sujeto). ${ }^{5}$ Es entonces la antes mencionada dimensión de independencia la que permite unificar todas las posturas realistas, desde Platón a Quine: cualesquiera que sean los tipos de entidades que constituyan la dimensión de existencia - esto es, cualesquiera que sean los tipos de entidades con los que se comprometa el realista: ya se trate de Ideas platónicas, formas aristotélicas, números, sentidos fregeanos, proposiciones, objetos físicos, etc.- , lo fundamental es que se respete la dimensión de independencia, esto es, que las entidades en cuestión no sean concebidas como si poseyeran una naturaleza mental y sean concebidas como objetivas, es decir, como existentes independientemente de las capacidades y facultades del sujeto. El realismo metafísico puede por tanto ser concebido como una teoría muy general, acerca de los tipos de objetos que existen en el mundo y acerca de cómo existen esos objetos; desde este punto de vista, no dice nada específico acerca de un tipo particular de objetos, a saber, las oraciones (o, en general, los portadores de verdad) y un tipo particular de propiedades, esto es, las propiedades semánticas, tales como la referencia y la verdad.

4 Véase Berkeley 1710.

5 Véanse Dummett 1975, 1976 y 1978. 
La teoría de la correspondencia, por su parte, es una teoría semántica acerca de la verdad, inspirada en la intuición de que la verdad es (o surge de) la correspondencia entre el lenguaje o el pensamiento, por un lado, y el mundo, por otro. Esta intuición ha dado origen a la teoría tradicional de la correspondencia, tal como se encuentra formulada en la obra de Platón y Aristóteles. ${ }^{6}$ Como es sabido, según la teoría en cuestión, la verdad de una oración puede ser definida como su correspondencia o adecuación a un hecho del mundo. Esta relación presenta las siguientes características: se trata de una relación asimétrica (va del mundo al lenguaje pero no a la inversa), de fundamentación (el lenguaje está fundado, fundamentado o anclado en el mundo) y con correlatos específicos (cada determinado hecho del mundo fundamenta determinada oración del lenguaje). Dado que tanto la noción de correspondencia o adecuación como la noción de hecho no resultan fácilmente explicables, gran parte de las versiones contemporáneas de la teoría de la correspondencia — tanto los enfoques atomísticos como la versión holística propuesta por Davidson - han apelado a la noción tarskiana de satisfacción, evitando de esta manera todo compromiso con la noción de hecho - a la que se considera carente de poder explicativo. ${ }^{7} \mathrm{El}$ enfoque atomístico convierte la noción tarskiana de satisfacción en el concepto empírico de referencia, definido en términos causales; la propuesta holística de Davidson, por su parte, niega que la noción en cuestión tenga contenido empírico

6 Véanse, por ejemplo, Sofista 26le5-263bl2, Metafísica, Libro IV, apartado VII y Libro IX, apartado X.

7 La noción de correspondencia había sido tradicionalmente explicada por medio de metáforas tales como la afirmación de que el lenguaje es un espejo o una pintura del mundo (véase, por ejemplo, la teoría pictórica del significado propuesta por Wittgenstein en el Tractatus Logico-Philosophicus). Respecto de la noción de hecho, se ha destacado que no puede ser explicada independientemente de la noción misma de verdad que intenta esclarecer (véase Davidson 1969). 
independientemente de la noción de verdad pero le atribuye un papel intrateórico fundamental en la asignación de condiciones veritativas. ${ }^{8}$ La teoría contemporánea de la correspondencia, tanto en su versión atomística como en su versión holística, es entonces una teoría de la representación o del significado; en otros términos, es una teoría de la verdad que identifica a esta última con la aptitud representacional de las oraciones del lenguaje. Su característica fundamental es que define la verdad como la propiedad que tienen las oraciones del lenguaje de representar al mundo, sean cuales fueren sus entidades constitutivas y el modo de existir de estas últimas.

Es cierto que tradicionalmente se creyó que el mundo con el que se corresponden las oraciones verdaderas era de naturaleza no mental y objetivo — en los sentidos antes señalados-: es cierto que tradicionalmente los defensores de la teoría de la verdad como correspondencia fueron asimismo defensores del realismo metafísico - en el sentido especificado anteriormente. Pero, considero que no debe confundirse lo que ha sido una unión histórica, desde los tiempos de Platón y Aristóteles, con una unión conceptual. ${ }^{9}$ Conceptualmente, la teoría de la verdad como correspondencia y el realismo metafísico son tan independientes entre sí como la metafísica aristotélica y la geometría euclideana, puesto que cabe pensar, en la línea de lo sugerido hasta aquí, que ninguna de las doctrinas

8 Para una defensa del enfoque atomístico, véanse Field 1972, Putnam 1975, Kripke 1980, Devitt 1974 y 1981, Devitt y Sterelny 1987. El enfoque holístico de Davidson es presentado paradigmáticamente en Davidson 1967.

9 Cabe destacar que lo que se atribuye, a mi entender erróneamente, a la concepción tradicional es que la teoría de la correspondencia incluye como parte constitutiva al realismo metafísico. La concepción de Putnam que intento criticar es, por el contrario, que el realismo metafísico incluye como parte constitutiva a la teoría de la correspondencia. 
mencionadas constituye un componente conceptual de la otra. ${ }^{10}$ Más específicamente, desde mi punto de vista, si hay alguna relación entre el realismo metafísico y la teoría de la verdad como correspondencia, la relación en cuestión no es conceptual sino empírica: dado el realismo metafísico, tal vez podría argumentarse que la mejor explicación del significado lingüístico es la ofrecida por la teoría correspondentista de la verdad — de acuerdo con esto, el argumento que permitiría pasar del realismo metafísico a la teoría de la correspondencia sería no una deducción, como pretende Putnam, sino una abducción o inferencia hacia la mejor explicación. $^{11}$

La fundamentación última de este punto de vista reside en la suscripción de la tesis general según la cual la metafísica es independiente respecto de la semántica. De acuerdo con esta postura, la metafísica se ocupa del mundo en general, mientras que la semántica se ocupa de una parte específica del mundo, a saber, aquélla constituida por el lenguaje (sea éste natural o mental), y, en particular, por el significado o la significación. Ahora bien, ¿por qué lo general habría de depender de lo particular? En términos más específicos, ¿por qué nuestra concepción acerca de lo que hay en general habría de estar en parte determinada por nuestra concepción acerca de algo tan específico como los significados lingüísticos? Si una determinada teoría semántica no funciona, ¿por qué por ello habría de modificarse nuestra concepción general del mundo? No parece haber ninguna razón sensata para que esto sea así. Lo razonable es, por el contrario, que las decisiones ontológicas particulares, entre las cuales se cuenta la concerniente a

10 En apoyo de esta idea, véanse, por ejemplo, Devitt 1991: Parte II; Barrio 1998: Parte II, cap. 3.

11 No es mi intención explayarme en el análisis de este argumento, que encuentro prima facie plausible. Para una fundamentación del mismo, véase Devitt 1991, cap. 4. 
los significados, se adecuen a un previo compromiso ontológico general. Si esto es así, la aceptación o el rechazo del compromiso ontológico general involucrado por el realismo metafísico no puede depender, como sostiene Putnam, de la aceptación o el rechazo respectivos de la teoría de la verdad como correspondencia, esto es, de una decisión ontológica particular relativa al significado lingüístico.

Con base en lo anterior, me interesa destacar dos puntos. En primer lugar, la aceptación del realismo metafísico es compatible con el rechazo de la teoría de la correspondencia, como muestran claramente todos aquellos que adhieren simultáneamente al realismo metafísico y a alguna teoría no correspondentista de la verdad, tal como la teoría deflacionaria - tal es el caso, por ejemplo, de Quine. ${ }^{12}$ Dicho de otro modo, es perfectamente posible aceptar el argumento modelo-teórico o algún otro argumento en contra de la correspondencia, como el argumento quineano de la indeterminación de la traducción, por ende renunciar a aquélla $\mathrm{y}$, sin embargo, seguir siendo un realista metafísico; nuevamente, es posible ser un eliminativista respecto de las propiedades semánticas sin ser un eliminativista respecto del mundo en general: si desaparecen las propiedades semánticas, jel resto del mundo no tiene por qué desaparecer junto con ellas! ${ }^{13}$

12 Véanse Quine 1960, 1969, 1970. Véase también Brandom 1988, quien combina el realismo metafísico con la defensa de una concepción pragmatista de la verdad.

13 Cabe destacar que la conjunción de realismo metafísico y deflacionismo acerca de la verdad podría a su vez compatibilizarse o bien con una actitud escéptica respecto de los significados o bien con la suscripción de una concepción epistémica del significado — en este último caso, el punto que hay que tener en cuenta es que no debe identificarse el significado con la verdad, dando lugar a una concepción también epistémica de esta última, a la manera de Dummett, identificación que parece desembocar inevitablemente en el antirrealismo metafísico. 
En segundo lugar, la aceptación de la teoría de la correspondencia es compatible con el rechazo del realismo metafísico, tal como ilustran quienes adhieren a la correspondencia pero sostienen una postura ontológica que, con base en la definición anterior, podría considerarse antirrealista, como es el caso, por ejemplo, del idealismo kantiano o trascendental. ${ }^{14}$ La teoría de la correspondencia es, por tanto, perfectamente compatible con el antirrealismo metafísico, entendido este último como la tesis general según la cual los objetos que integran el mundo o bien son de naturaleza mental o bien dependen (aunque sea en parte) de las capacidades y estructuras del sujeto para existir.

Cabe aclarar que soy plenamente consciente de que la presentación anterior no refleja la manera habitual de caracterizar al realismo metafísico en la filosofía contemporánea: la enorme influencia del giro lingüístico ha hecho que, en este siglo, la discusión en torno al realismo metafísico esté sistemáticamente dominada por el planteo del problema de la verdad. De ahí que la mayor parte de las caracterizaciones contemporáneas del realismo metafísico se hayan hecho, a la manera de Putnam, en términos de la noción de verdad. ${ }^{15}$ En mi opinión, sin embargo, esto constituye un error: dada su naturaleza general, las cuestiones metafísicas no están conceptualmente ligadas a cuestiones semánticas sino que son previas a ellas; por lo tanto, no es adecuado utilizar nociones semánticas, como la idea de verdad, en el

14 Véase Kant 1787, tomo I.

15 Como otro ejemplo de esta estrategia puede citarse el siguiente texto de Platts: "El sello del realismo, como el término se usa aquí, es éste: la aplicabilidad del predicado-de-verdad a una oración está determinada por la realidad extralingüística - excepto, por supuesto, respecto de las oraciones acerca del lenguaje." Platts 1979, p. 57. Véase también el denominado "realismo alético" en Alston 1996. 
planteamiento de cuestiones metafísicas, como el problema del realismo. ${ }^{16}$

En síntesis, si la relación entre el realismo metafísico y la teoría de la correspondencia no es conceptual, entonces un argumento en contra de ésta última, como el argumento modelo-teórico, no puede ser interpretado como un argumento en contra del primero: la refutación del realismo metafísico no puede hacerse, como pretende Putnam, deduciendo el ataque de un ataque a la correspondencia. En términos más específicos, la indeterminación de la referencia y el significado, presuntamente establecida por el argumento modelo-teórico, no es suficiente para concluir, como pretende Putnam, el carácter interno del mundo. Si hemos de aceptar, en virtud de la primera, que existen múltiples descripciones verdaderas y que cada una de ellas expresa un distinto esquema referencial, ¿por qué habríamos de concluir que lo descrito es en cada caso algo de cierta manera "interno" a la mente o constituido por ella? Las consecuencias de la indeterminación no tienen por qué ser tan drásticas.

Como conclusión, la objeción referida al alcance del argumento modelo-teórico desarrollada en este apartado intenta establecer que el argumento en cuestión, aun cuando fuere exitoso en contra de la correspondencia, no lograría afectar el realismo metafísico. En tanto argumento semántico, es insuficiente para establecer una tesis metafísica general, a saber, el rechazo del realismo metafísico y la consiguiente defensa del realismo interno. La idea general subyacente es que las tesis ontológicas son independientes de las tesis

16 Del mismo modo, considero que la adopción de una estrategia ontológica en semántica, esto es, la derivación de una tesis ontológica a partir de una tesis semántica, además de no estar justificada más que históricamente, tiene la desventaja de oscurecer notablemente tanto el terreno de la metafísica como el de la semántica, complicando innecesariamente a cada uno de ellos con problemas que no les son propios. 
semánticas y deben ser establecidas no mediante argumentos semánticos, como el modelo-teórico, sino mediante argumentos ontológicos. En mi opinión, las tesis ontológicas dependen de decisiones ontológicas. Mi propósito presente ha sido mostrar que Putnam no constituye una excepción a la regla: el problema con él es que, una vez descalificado el argumento modelo-teórico, su decisión en favor del realismo interno parece quedarse sin justificación alguna - pero este punto excede obviamente los límites de este trabajo.

\section{El argumento basado en el perspectivismo}

El otro de los argumentos ofrecidos por Putnam en contra del realismo metafísico que me interesa analizar puede caracterizarse como "argumento basado en el perspectivismo". Con el término "perspectivismo", me refiero a la idea de que el mundo puede ser visto desde múltiples perspectivas y descrito de distintas maneras, es decir, lo que constituye la tesis central del relativismo conceptual. El argumento en cuestión puede ser reconstruido en los siguientes términos:

(1) Si el realismo metafísico es verdadero, entonces hay una única descripción completa y verdadera del mundo.

(2) No es cierto que haya una única descripción completa y verdadera del mundo.

Luego, (3) el realismo metafísico no es verdadero.

Está claro que lo que otorga fundamento a la premisa (1) es la antes mencionada concepción putnamiana del realismo metafísico, según la cual:

(a) éste incluye como parte constitutiva a cierta teoría acerca de la verdad, la teoría de la verdad como correspondencia; 
(b) la teoría de la correspondencia involucra a su vez la tesis de que hay una única descripción verdadera del mundo.

Ahora bien, en mi opinión, el problema de este argumento es precisamente la falsedad de lo presupuesto por dicha premisa: en primer lugar, es falso que el realismo metafísico incluya como parte constitutiva la teoría de la correspondencia, por lo que aceptar el realismo metafísico no implica aceptar nada acerca de lo que es ser verdadero; en segundo lugar, también es falsa la tesis de que la teoría de la correspondencia involucra la existencia de una única descripción del mundo, por lo que aun cuando se pensare, a la manera de Putnam, que el realismo metafísico implica lógicamente a la teoría de la correspondencia, ello no conduciría a la conclusión de que el realismo metafísico es incompatible con el perspectivismo o relativismo conceptual. De este modo, en lo que concierne a (a), cabe recordar lo que se intentó fundamentar en el apartado anterior: la idea de que una concepción más adecuada del realismo metafísico debería excluir toda tesis semántica, en particular toda tesis acerca de la verdad. Como señalé anteriormente, considero que el realismo metafísico no nos compromete necesariamente con la existencia de una única descripción verdadera del mundo por una simple razón: es plausible (y más sensato) pensar, contrariamente a lo sostenido por Putnam, que el realismo metafísico es una teoría metafísica acerca de la naturaleza del mundo, conceptualmente independiente de toda tesis semántica y epistemológica acerca de los aspectos parciales de aquél que incluye a las capacidades semánticas, epistémicas y pragmáticas de los seres humanos - y tal vez de otros objetos funcionalmente semejantes a ellos. Considero entonces que se han expuesto razones suficientes para rechazar (a). En este apartado, me propongo entonces 
argumentar en contra de la subtesis de que la teoría de la correspondencia nos compromete necesariamente con la existencia de una única descripción completa y verdadera del mundo - esto es, intentaré dar razones para rechazar (b).

Para Putnam, el realismo metafísico es claramente una postura no-relativista. Por un lado, los objetos del mundo no son relativos o no existen relativamente a la adopción de determinados puntos de vista (sean éstos de individuos, grupos sociales, comunidades lingüísticas, sociedades, momentos históricos, etc.), por lo que puede decirse que el realismo metafísico no involucra ningún tipo de relativismo ontológico. Más aun, en la medida en que tampoco nuestras descripciones de los objetos son relativas a la adopción de tales puntos de vista sino que revelan el antes mencionado punto de vista trascendente del Ojo de Dios, Putnam concluye que el realismo metafísico tampoco involucra el relativismo conceptual en ninguna de sus versiones. Ahora bien, en mi opinión, lo primero es verdadero pero lo segundo es falso; en particular, no es correcto considerar que el rechazo del relativismo ontológico, característico del realismo metafísico, constituye un fundamento suficiente para el rechazo del relativismo conceptual - esto es, del perspectivismo. ${ }^{17}$ Explicaré esto último con más detalle.

Considero que la conjunción empírica (en virtud de lo argumentado anteriormente) del realismo y la correspondencia es perfectamente compatible con la existencia de descripciones alternativas, todas ellas igualmente verdaderas, que expresan distintas perspectivas epistémicas o distintas maneras de conceptualizar el mundo. El punto a destacar

17 Cabe aclarar que, en lo que sigue y sobre la base de lo argumentado en el apartado anterior, consideraré que el vínculo entre el realismo metafísico y la teoría de la verdad como correspondencia no es conceptual, deductivo o necesario sino empírico, no deductivo o contingente. 
es que las descripciones en cuestión dependen no sólo de lo que existe sino también de cómo un individuo o un grupo de individuos decide describir lo que existe en función de sus creencias, conocimientos e intereses tanto teóricos como prácticos. En otras palabras, si bien es cierto que, para el realista metafísico, por un lado, el mundo externo restringe el conjunto de descripciones posibles, también es cierto que, por otro, hay cierto margen de libertad: el realista no puede considerar al ser humano libre de crear el mundo en que vive, puesto que, desde su perspectiva, éste existe de manera objetiva, independientemente de sus capacidades constitutivas; pero sí puede considerarlo libre de nombrar las propiedades del mundo que más le interesen.

Para tomar un ejemplo conocido: para un habitante del Polo Norte puede ser muy útil en la vida práctica disponer de un término distinto para cada matiz diferente de nieve, mientras que para un habitante del Amazonas resulta útil contar con varios términos para los variados tonos de verde. Pero afirmar que la comunidad lingüística lapona ha sido libre de inventar múltiples términos de nieve no equivale en absoluto a afirmar que ha inventado variedades de nieve que sólo existen en el Polo Norte. Del mismo modo, las comunidades amazónicas podrán ser libres de inventar múltiples términos de verde pero no por ello habrán de aumentar los verdes del mundo. Un último ejemplo: para un comerciante A puede ser útil inventar un término para nombrar a todo aquel cliente que gaste mensualmente cierta cantidad de dinero en sus productos, tal como, "clientol": de acuerdo con esto, un clientol es aquella persona que es cliente del negocio de A y adquiere allí productos mensualmente por una suma de dinero. La categorización de los seres humanos como clientoles o no clientoles es muy importante para A pero absolutamente irrelevante para casi todo el resto de los mortales; se trata por tanto de una descripción del mundo relativa a A y a su visión particular 
del mundo o a su esquema conceptual. Esto no implica en modo alguno que los clientoles dependan en cuanto a su existencia de las capacidades de A: los clientoles existen objetivamente, son parte del mundo. A decide agrupar los objetos del mundo de determinada manera, inventa el término "clientol" para esa clasificación, pero no crea, en ningún sentido de la palabra, a los clientoles.

En otros términos, de la idea de que los objetos/propiedades del mundo existen independientemente de nuestras diversas capacidades constitutivas (tesis central del realismo metafísico) y la idea de que la verdad surge de la correspondencia entre nuestros conceptos y esos objetos/propiedades (núcleo básico de la teoría de la correspondencia) no se sigue que las relaciones de correspondencia en cuestión sean únicas y universales. Por un lado, hay objetos; por otro, hay mentes; finalmente, hay correlaciones biunívocas entre los primeros y las segundas. Pero me parece que el realista metafísico puede esgrimir dos tesis para impedir que su compromiso ontológico implique la adopción del controvertido punto de vista epistémico del Ojo de Dios: (i) uno tiene libertad para nombrar ciertos objetos/propiedades y no otros; (ii) uno tiene libertad para agrupar los objetos/propiedades de distintas maneras. Estas libertades tienen que ver con los intereses personales y comunitarios que el realista metafísico defensor de la correspondencia no tiene por qué dejar de lado. Si se toma en cuenta que la teoría de la correspondencia es una teoría del significado, la misma idea puede expresarse en los siguientes términos: hay una libertad para identificar significados que no debe confundirse con la libertad de crearlos. Dar cabida a la primera no implica por tanto "internalizar" ni la correspondencia ni el mundo - como sugiere Putnam. En virtud de estas consideraciones, no es plausible afirmar que el realismo metafísico, en conjunción 
con la teoría de la correspondencia, es perfectamente compatible con el perspectivismo o relativismo conceptual.

En síntesis, con base tanto en las consideraciones recientes como en las del apartado anterior, considero que el argumento apoyado en el perspectivismo no es bueno porque no hay razones suficientes para aceptar su primera premisa: por el contrario, ésta presupone una caracterización del realismo metafísico que es inadecuada porque introduce conceptos semánticos (como el de descripción verdadera) y epistemológicos (como el del punto de vista del Ojo de Dios) que son fundamentalmente ajenos a la tesis realista.

Por lo demás, cabe tener en cuenta lo siguiente. Para Putnam, el único modo de dar cabida al perspectivismo es mediante la defensa del denominado "realismo interno". El realismo interno o perspectiva internalista es caracterizado por el autor mediante las siguientes tesis:

(i) los objetos del mundo sólo existen en relación con/ dentro de una cierta descripción o una cierta teoría acerca de él;

(ii) hay múltiples descripciones o teorías verdaderas acerca del mundo (el concepto de verdad involucrado debe entenderse en términos de aceptabilidad racional idealizada, es decir, en términos epistémicos).

De acuerdo con esto, puede decirse que las múltiples maneras de describir al mundo corresponden a las múltiples maneras de constituirlo a partir del material originariamente dado a los sentidos (inputs experienciales o sense-data). De este modo, el realismo interno, a diferencia del realismo metafísico, constituye un claro ejemplo de relativismo ontológico: los objetos existen relativamente a las capacidades humanas de constituirlos; como consecuencia de ello, los distintos mundos constituidos dan origen a distintas descripciones y teorías. Para Putnam es claro que los objetos 
no existen de manera objetiva, puesto que están constituidos por el sujeto (a la manera de los fenómenos kantianos), siendo su existencia relativa a las capacidades subjetivas. ${ }^{18}$ Por consiguiente, no se respeta una de las dimensiones fundamentales del realismo metafísico: la mencionada dimensión de independencia. El carácter interno del realismo putnamiano permite considerar a esta postura como una nueva versión del antirrealismo metafísico - con un nombre un poco paradójico. Ahora bien, a la luz de estas consideraciones es posible entonces reformular la conclusión anterior en los siguientes términos: el perspectivismo o relativismo conceptual no requiere, como parece sostener Putnam, el antirrealismo del relativismo ontológico - por el contrario, según los argumentos previos, es posible sostener que se trata de una postura compatible con el realismo metafísico.

Por último, cabe destacar que, también paradójicamente, el relativismo conceptual involucrado por la perspectiva internalista no resulta significativo: si las capacidades constitutivas son comunes a la especie humana, entonces no puede esperarse que los objetos del mundo, relativos en cuanto a su existencia a dichas capacidades, difieran significativamente entre sí. Y, dado que la capacidad descriptiva se ajusta, según Putnam, a tales objetos, tampoco lo harán las descripciones resultantes. Parecería tratarse entonces de un relativismo ontológico específico (de inspiración kantiana), demasiado general como para introducir el ansiado perspectivismo: la única perspectiva introducida es la común a la especie humana.

En síntesis, suscribir el antirrealismo metafísico no es, como cree Putnam, la única ni la mejor manera de dar cabida al perspectivismo; lejos de ello, es posible ser perspectivista o relativista conceptual y mantener, al mismo

18 Véase, por ejemplo, Putnam 1988, cap. 7. 
tiempo, el compromiso realista. Por consiguiente, la verdad del perspectivismo no ofrece, como quiere Putnam, una vía argumental en contra del realismo metafísico.

\section{Conclusión}

En mi opinión, el ataque de Putnam al realismo metafísico, tal como se manifiesta en los dos argumentos considerados en este trabajo, conlleva un grave error estratégico: si se quiere atacar al realismo metafísico, no debe tomarse como objetivo la teoría de la verdad como correspondencia. La caída de la correspondencia no tiene por qué afectar nuestras convicciones realistas acerca del mundo. En otras palabras, una postura metafísica general como el realismo metafísico sólo puede ser abandonada sobre la base de una decisión metafísica general. ${ }^{19}$

\section{BIBLIOGRAFÍA}

Alston, William, 1996, A Realist Conception of Truth, Cornell University Press, Ítaca.

Aristóteles, 1993, Metafísica, versión en castellano de Patricio de Azcárate, Espasa Calpe, Madrid.

Barrio, Eduardo, 1998, La verdad desestructurada, Eudeba, Enciclopedia Lógica, Buenos Aires.

19 Una primera versión de este trabajo fue leída en el II Coloquio de Jóvenes Filósofos titulado El relativismo: aspectos teóricos y prácticos de la discusión, celebrado en Buenos Aires, del 2 al 4 de septiembre de 1996. Agradezco a Guillermo Hurtado y a Plinio Junqueira Smith por haberme hecho múltiples e interesantes comentarios críticos en ocasión de ese encuentro. Con posterioridad, este tema fue discutido en las reuniones periódicas celebradas en el marco de distintos proyectos de investigación subsidiados por la Universidad de Buenos Aires. Agradezco también a los miembros de esos proyectos, Eduardo Barrio, Juan Comesaña, Federico Penelas y Carolina Sartorio, por las intensas discusiones que mantuvieron vivo mi interés por el tema e inspiraron la redacción final de este trabajo. 
Berkeley, George, 1980, Principios del conocimiento humano, versión en castellano de Pablo Masa, Aguilar, Buenos Aires (1710).

Brandom, Robert, 1988, "Pragmatism, Phenomenalism and Truth Talk", en P. French, T. Uehling y H. Wettstein (comps.), Midwest Studies in Philosophy, vol. XII, Realism and Antirealism, University of Minnesota Press, Minneapolis.

Davidson, Donald, 1984, Inquiries into Truth and Interpretation, Oxford University Press, Nueva York.

-(1970), "Semantics for Natural Languages", en Davidson 1984.

- (1969), "True to the Facts", en Davidson 1984.

(1967), "Truth and Meaning", en Inquiries into Truth and Interpretation, Oxford University Press, Nueva York, 1984

Devitt, Michael, 1991, Realism and Truth, 2da. edición revisada, Basil Blackwell, Oxford.

—_, 1981, Designation, Columbia University Press, Nueva York.

—_, 1974, "Singular Terms", The Journal of Philosophy, 71.

—, and Kim Sterelny, 1997, Language and Reality: An Introduction to the Philosophy of Language, 2da. edición revisada, Basil Blackwell, Oxford (1987) .

Dummett, Michael, 1990, "La verdad" en La verdad y otros enigmas, versión en castellano de Alfredo Herrera Patiño, Fondo de Cultura Económica, México (1959).

—_ 1978, Truth and Other Enigmas, Harvard University Press, Cambridge, MA.

_ , 1976, "What is a Theory of Meaning?" (II), Truth and Meaning: Essays in Semantics, en Gareth Evans y John McDowell (comps.), Clarendon Press, Oxford.

—, 1975, "What is a Theory of Meaning?", Mind and Language, en Samuel Guttenplan (comp.), Clarendon Press, Oxford.

Etchemendy, John, 1988, "Tarski on Truth and Logical Consequence", The Journal of Symbolic Logic, vol. 53, no. 1.

Field, Hartry, 1994, "Deflationist Views of Meaning and Content", Mind, vol. 103, no. 411.

—_, 1986, "The Deflationary Conception of Truth", en McDonald y Wright (comps.), Fact, Science and Value, Basil Blackwell, 
— 1972, "Tarski's Theory of Truth", The Journal of Philosophy, 69.

Horwich, Paul, 1990, Truth, Basil Blackwell, Oxford.

Kant, Immanuel, 1983, Crítica de la razón pura, versión en castellano de José del Perojo, Losada, Buenos Aires (1787), tomo I.

Kripke, Saul, 1980, El nombrar y la necesidad, versión en castellano de Margarita Valdés, México, unam, 1985.

Leeds, Stephen, 1978, "Theories of Reference and Truth", Erkenntnis, vol. 13.

Orayen, Raúl, 1989, Lógica, significado y ontología, México, UNAM, cap. 3.

Platón, Sofista en Diálogos V, 1988, versión en castellano de Ma. Isabel Santa Cruz, Alvaro Vallejo Campos y Néstor Cordero, Gredos, Madrid.

Platts, Mark, 1992, Sendas del significado, Fondo de Cultura Económica/unam, México (1979).

Putnam, Hilary, 1994, Words and Life, Harvard University Press, Cambridge.

— Gabriela Ventureira, Gedisa, Barcelona, 1990.

__, 1981, Reason, Truth and History, Cambridge University Press, Cambridge.

- 1978, Meaning and the Moral Sciences, Routledge and Kegan Paul, Londres.

_- 1975, Mind, Language and Reality: Philosophical Papers, vol. 2, Cambridge University Press, Cambridge.

Quine, Willard Van Orman, 1970, Filosofía de la lógica, versión en castellano de Manuel Sacristán, Alianza, Madrid, 1973, cap. 3.

— 1969, "Ontological Relativity", en Ontological Relativity and Other Essays, Columbia University Press, New York.

- 1960, Word and Object, The MIT Press, Cambridge, cap. 2.

Soames, Scott, 1984, "What is a Theory of Truth?", The Journal of Philosophy, 81, no. 8. 


\section{SUMMARY}

In Reason, Truth and History, Putnam argues against metaphysical realism and thus proposes to substitute it with a new ontological conception, the so-called "internal realism". In my opinion, his main arguments against metaphysical realism are the following: on the one hand, the model-theoretic argument; on the other, an argument based on the non existence of a unique true description of the world that might be named "argument from perspectivism". In this paper, I intend to defend the thesis that both arguments are affected by the same kind of problem: namely, they wrongly assume metaphysical realism to necessarily involve certain doctrines, more specifically, the correspondence theory of truth and the thesis of the existence of a unique true description of the world. I try to argue that, Putnam's opinion notwithstanding, metaphysical realism is conceptually independent of both doctrines; I then conclude that Putnam's arguments against it, mainly aimed at them, have failed to achieve their purpose. 